\title{
Towards optimized viral metagenomes for double-stranded and single-stranded DNA viruses from challenging soils
}

Gareth Trubl $^{1,2}$, Simon Roux ${ }^{3}$, Natalie Solonenko ${ }^{1}$, Yueh-Fen Li ${ }^{1}$, Benjamin Bolduc ${ }^{1}$, Josué Rodríguez-Ramos ${ }^{1,4}$, Emiley A. Eloe-Fadrosh ${ }^{3}$, Virginia I. Rich ${ }^{\text {Corresp., } 1}$, Matthew B. Sullivan $^{\text {Corresp. 1, } 5}$

1 Department of Microbiology, Ohio State University, Columbus, Ohio, United States

2 Physical and Life Sciences Directorate, Lawrence Livermore National Laboratory, Livermore, California, United States

3 United States Department of Energy Joint Genome Institute, Lawrence Berkeley National Laboratory, Walnut Creek, California, United States

4 Department of Soil and Crop Sciences, Colorado State University, Fort Collins, Colorado, United States

${ }^{5}$ Department of Civil, Environmental and Geodetic Engineering, The Ohio State University, Columbus, Ohio, United States

Corresponding Authors: Virginia I. Rich, Matthew B. Sullivan

Email address: virginia.isabel.rich@gmail.com, mbsulli@gmail.com

Soils impact global carbon cycling and their resident microbes are critical to their biogeochemical processing and ecosystem outputs. Based on studies in marine systems, viruses infecting soil microbes likely modulate host activities via mortality, horizontal gene transfer, and metabolic control. However, their roles remain largely unexplored due to technical challenges with separating, isolating, and extracting DNA from viruses in soils. Some of these challenges have been overcome by using whole genome amplification methods and while these have allowed insights into the identities of soil viruses and their genomes, their inherit biases have prevented meaningful ecological interpretations. Here we experimentally optimized steps for generating quantitatively-amplified viral metagenomes to better capture both SsDNA and dsDNA viruses across three distinct soil habitats along a permafrost thaw gradient. First, we assessed differing DNA extraction methods (PowerSoil, Wizard mini columns, and cetyl trimethylammonium bromide) for quantity and quality of viral DNA. This established PowerSoil as best for yield and quality of DNA from our samples, though $\sim 1 / 3$ of the viral populations captured by each extraction kit were unique, suggesting appreciable differential biases among DNA extraction kits. Second, we evaluated the impact of purifying viral particles after resuspension (by cesium chloride gradients; $\mathrm{CsCl}$ ) and of viral lysis method (heat vs bead-beating) on the resultant viromes. DNA yields after $\mathrm{CsCl}$ particle-purification were largely non-detectable, while unpurified samples yielded 1-2-fold more DNA after lysis by heat than by bead-beating. Virome quality was assessed by the number and size of metagenome-assembled viral contigs, which showed no increase after $\mathrm{CsCl}$-purification, but did from heat lysis relative to bead-beating. We also evaluated sample preparation protocols for sSDNA virus recovery. In both CsCl-purified and non-purified samples, ssDNA viruses were successfully 
recovered by using the Accel-NGS $1 S$ Plus Library Kit. While ssDNA viruses were identified in all three soil types, none were identified in the samples that used bead-beating, suggesting this lysis method may impact recovery. Further, 13 ssDNA vOTUs were identified compared to 582 dsDNA vOTUs, and the ssDNA vOTUs only accounted for $\sim 4 \%$ of the assembled reads, implying dsDNA viruses were dominant in these samples. This optimized approach was combined with the previously published viral resuspension protocol into a sample-to-virome protocol for soils now available at protocols.io, where community feedback creates 'living' protocols. This collective approach will be particularly valuable given the high physicochemical variability of soils, which will may require considerable soil type-specific optimization. This optimized protocol provides a starting place for developing quantitatively-amplified viromic datasets and will help enable viral ecogenomic studies on organic-rich soils. 
1 Towards optimized viral metagenomes for double-stranded and single-stranded DNA viruses

2 from challenging soils

3

4 Gareth Trubl ${ }^{1 \dagger}$, Simon Roux ${ }^{2}$, Natalie Solonenko ${ }^{1}$, Yueh-Fen $\mathrm{Li}^{1}$, Benjamin Bolduc ${ }^{1}$; Josué

5 Rodríguez-Ramos ${ }^{1, \#}$, Emiley Eloe-Fadrosh², Virginia I. Rich ${ }^{1}$, Matthew B. Sullivan ${ }^{1,3}$

${ }^{1}$ Department of Microbiology, The Ohio State University, Columbus, $\mathrm{OH}$, United States

${ }^{2}$ United States Department of Energy Joint Genome Institute, Lawrence Berkeley National

${ }^{3}$ Department of Civil, Environmental and Geodetic Engineering, The Ohio State University, Laboratory, Livermore, CA, United States

\#Current address: Department of Soil and Crop Sciences, Colorado State University, Fort Collins, CO, United States

Correspondence to:

Matthew B. Sullivan and Virginia I. Rich

496 W. 12th Ave, 914 Riffe Building, Columbus OH, 43210

Email addresses: mbsulli@gmail.com; virginia.isabel.rich@gmail.com

8

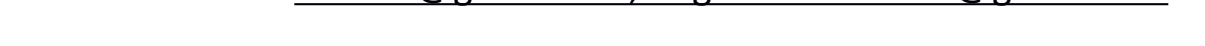




\section{Abstract}

Soils impact global carbon cycling and their resident microbes are critical to their biogeochemical processing and ecosystem outputs. Based on studies in marine systems, viruses infecting soil microbes likely modulate host activities via mortality, horizontal gene transfer, and metabolic control. However, their roles remain largely unexplored due to technical challenges with separating, isolating, and extracting DNA from viruses in soils. Some of these challenges have been overcome by using whole genome amplification methods and while these have allowed insights into the identities of soil viruses and their genomes, their inherit biases have prevented meaningful ecological interpretations. Here we experimentally optimized steps for generating quantitatively-amplified viral metagenomes to better capture both ssDNA and dsDNA viruses across three distinct soil habitats along a permafrost thaw gradient. First, we assessed differing DNA extraction methods (PowerSoil, Wizard mini columns, and cetyl trimethylammonium bromide) for quantity and quality of viral DNA. This established PowerSoil as best for yield and quality of DNA from our samples, though $\sim 1 / 3$ of the viral populations captured by each extraction kit were unique, suggesting appreciable differential biases among DNA extraction kits. Second, we evaluated the impact of purifying viral particles after resuspension (by cesium chloride gradients; $\mathrm{CsCl}$ ) and of viral lysis method (heat vs beadbeating) on the resultant viromes. DNA yields after $\mathrm{CsCl}$ particle-purification were largely nondetectable, while unpurified samples yielded 1-2-fold more DNA after lysis by heat than by bead-beating. Virome quality was assessed by the number and size of metagenome-assembled viral contigs, which showed no increase after $\mathrm{CsCl}$-purification, but did from heat lysis relative to bead-beating. We also evaluated sample preparation protocols for ssDNA virus recovery. In both $\mathrm{CsCl}$-purified and non-purified samples, ssDNA viruses were successfully recovered by using the Accel-NGS 1S Plus Library Kit. While ssDNA viruses were identified in all three soil types, none were identified in the samples that used bead-beating, suggesting this lysis method may impact recovery. Further, 13 ssDNA vOTUs were identified compared to 582 dsDNA vOTUs, and the sSDNA vOTUs only accounted for $\sim 4 \%$ of the assembled reads, implying dsDNA viruses were dominant in these samples. This optimized approach was combined with the previously published viral resuspension protocol into a sample-to-virome protocol for soils now available at protocols.io, where community feedback creates 'living' protocols. This collective approach will be particularly valuable given the high physicochemical variability of soils, which will may require considerable soil type-specific optimization. This optimized protocol provides a starting place for developing quantitatively-amplified viromic datasets and will help enable viral ecogenomic studies on organic-rich soils.

\section{Introduction}

Optimization of experimental methods to generate viral-particle metagenomes (viromes) from aquatic samples has enabled robust ecological analyses of marine viral communities (reviewed in Brum and Sullivan 2015; Sullivan, Weitz, and Wilhelm 2016; Hayes et 
al. 2017). In parallel, optimization of informatics methods to identify and characterize viral sequences has advanced viral sequence recovery from microbial-cell metagenomes, as well as virome analyses (Edwards and Rohwer 2005; Wommack et al. 2012; Roux et al. 2015; Brum \& Sullivan, 2015; Roux et al. 2016; Bolduc et al. 2016; Ren et al. 2017; Amgarten et al. 2018; Gregory et al. 2019). Application of these methods with large-scale sampling (Brum et al. 2015; Roux et al. 2016) has revealed viruses as important members of ocean ecosystems acting through host mortality, gene transfer, and direct manipulation of key microbial metabolisms including photosynthesis and central carbon metabolism during infection, via expression of viral-encoded 'auxiliary metabolic genes' (AMGs). More recently, the abundance of several key viral populations was identified as the best predictor of global carbon (C) flux from the surface oceans to the deep sea (Guidi et al. 2016). This finding suggests that viruses may play a role beyond the viral shunt and help form aggregates that may store $\mathrm{C}$ long-term. These discoveries in the oceans have caused a paradigm shift in how we view viruses: no longer simply disease agents, it is now clear that viruses play central roles in ocean ecosystems and help regulate global nutrient cycling.

In soils, however, viral roles are not so clear. Soils contain more $C$ than all the vegetation and the atmosphere combined (between 1500-2400 gigatons; Lehmann and Kleber 2015), and soil viruses likely also impact C cycling, as their marine counterparts do. However, our knowledge about soil viruses remains limited due to the dual challenges of separating viruses from the highly heterogeneous soil matrix, while minimizing DNA amplification inhibitors (e.g. humics; reviewed in Williamson et al. 2017). For these reasons, most soil viral work is limited to direct counts and morphological analyses (i.e. microscopy observations), from which we have learned (i) there are $10^{7}-10^{9}$ virus-like particles/g soil, (ii) viral morphotype richness is generally higher in soils than in aquatic ecosystems, and (iii) viral abundance correlates with soil moisture, organic matter content, $\mathrm{pH}$, and microbial abundance (reviewed in Williamson 2017; Narr et al. 2017). The minimal collective metagenomic data for soils suggests that genetic diversity of soil viruses far exceeds that of other environments for which virome data are available and these viral communities are localized in that viruses form habitat-specific groups (Fierer et al. 2007; Kim et al. 2008; Srinivasiah et al. 2015; Reavy et al. 2015; Zablocki et al. 2016; Trubl et al. 2018; Emerson et al. 2018; Green et al. 2018). Thus, while sequencing data for soil viruses is not as robust as it is in aquatic environments, such high particle counts and patterns suggest that viruses also play important ecosystems roles in soils.

The first barrier to obtaining sequence data for soil viruses is simply separating the viral particles from the soil matrix, and then accessing their nucleic acids. Viral resuspension is unlikely to be universally solvable with a single approach due to high variability of soil properties (e.g. mineral content and cation exchange capacity) impacting virus-soil interactions. There have been independent efforts to optimize virus resuspension methods tailored to specific soil types, and employing a range of resuspension methods (reviewed in Narr et al. 2017; Pratama and van Elsas, 2018). Once viruses are separated, extraction of their DNA must surmount the additional challenges of co-extracted inhibitors (hampering subsequent 
117 molecular biology, as previously described for soil microbes; Narayan et al. 2016; Zielińska et al.

118

119

120

121

122

123

124

125

126

127

128

129

130

131

132

133

134

135

136

137

138

139

140

141

142

143

144

145

146

147

148

149

150

151

152

153

154

155
2017), and low DNA yields.

Extracting viral nucleic acid from soils typically results in very low DNA yields, requiring amplification prior to sequencing. Amplification of viral nucleic acid is necessary because the high heterogeneous nature of soil prevents any meaningful viral ecology if DNA yield is increased by increasing the number of virus extractions and pooling the concentrate (microscale variation and the need for smaller-scale sampling reviewed in Fierer 2017). Two widely used methods to amplify viral nucleic acid are multiple displacement amplification (MDA; 'whole genome' amplification using the phi29 polymerase) and random priming-mediated sequence-independent single-primer amplification (RP-SISPA). Both allow qualitative observations of viral sequences but preclude quantitative ecological inferences. Specifically, MDA causes dramatic shifts in relative abundances of DNA templates, which impact subsequent estimates of viral populations diversity, and, most dramatically, over-amplify ssDNA viruses (Binga, Lasken, and Neufeld, 2008; Yilmaz, Allgaier, and Hugenholtz 2010; Kim, Whon, and Bae 2013; Marine et al. 2014). RP-SISPA is biased towards the most abundant viruses or largest genomes, and leads to uneven coverage along the amplified genomes (Karlsson, Belák, and Granberg 2013).More recently, quantitative amplification methods have emerged that use transposon-mediated tagmentation (Nextera, for dsDNA; Trubl et al. 2018; Segobola et al. 2018) or acoustic shearing to fragment and a custom adaptase (Accel-NGS 1S Plus, for dsDNA and ssDNA; Roux et al. 2016; Rosario et al. 2018) to ligate adapters to DNA templates, before PCR amplification is used to obtain enough material for sequencing. These approaches have successfully amplified as little as 1 picogram (Nextera XT; Rinke et al. 2016) and 100 nanograms (Accel-NGS 1S Plus; Kurihara et al. 2014) of input DNA for viromes while maintaining the relative abundances of templates.

We previously optimized a viral resuspension method for three peat soil habitats (palsa, bog, and fen, spanning a permafrost thaw gradient; Trubl et al. 2016). Given emerging quantitative low-input DNA library construction options, we sought here to characterize how the choice of methods for viral particle purification, lysis and DNA extraction impacted viral DNA yield and quality, and resulting virome diversity. The objectives of this work were to (1) optimize the generation of viromes from soils and (2) evaluate the capability of the Accel-NGS 1S Plus kit to quantitatively amplify ssDNA and dsDNA viruses from soils. We conducted two independent experiments testing three different DNA extraction methods (Experiment 1), and then two virion lysis methods with and without further particle purification (Experiment 2). Because microscopy is not sufficient for assessing the presence of non-viral particles, we employed a combination of qPCR and virus-specific bioinformatics to evaluate the success of this protocol to yield genuine viral genomes. Quantitative soil viromes for both SSDNA and dsDNA viruses were generated, enabling a robust comparison of the different protocols tested.

\section{Methods}

Field site and sampling 
156

157

158

159

160

161

162

163

164

165

166

167

168

169

170

171

172

173

174

175

176

177

178

179

180

181

182

183

184

185

186

187

188

189

190

191

192

193

194

195

Stordalen Mire $\left(68.35^{\circ} \mathrm{N}, 19.05^{\circ} \mathrm{E}\right)$ is a peat plateau in Arctic Sweden in a zone of discontinuous permafrost. Peat depth ranges from 1-3 meters (Johansson et al. 2006; Normand et al. 2017). Habitats broadly span three stages of permafrost thaw: palsa (drained soil, dominated by small shrubs, and underlain by intact permafrost; $\mathrm{pH} \sim 6.50$ ), bog (partially inundated peat, dominated by Sphagnum moss, and underlain by partially thawed permafrost; $\mathrm{pH} \sim 4.10$ ), and fen (fully inundated peat, dominated by sedges, and with no detectable permafrost at <1 m; pH 5.70) (further described in Hodgkins et al. 2014). These soils vary chemically (Hodgkins et al., 2014; Normand et al. 2017; Wilson et al. 2017), hydraulically (Christensen et al. 2004; Malmer et al. 2005; Olefeldt et al. 2012; Jonasson et al. 2012), and biologically (Mondav et al. 2014; McCalley et al. 2014; Mondav et al. 2017; Woodcroft et al. 2018), creating three distinct habitats with increasing organic matter lability with permafrost thaw. Soil was collected with an $11 \mathrm{~cm}$-diameter custom circular push corer at palsa sites, and with a $10 \mathrm{~cm} \times 10 \mathrm{~cm}$ square Wardenaar corer (Eijkelkamp, The Netherlands) at the bog and fen sites. Three cores from each habitat were processed using clean techniques described previously (Trubl et al. 2016) and cut in five-centimeter increments from 1-40 cm for palsa and $1-80 \mathrm{~cm}$ for bog and fen cores. Samples were flash-frozen in liquid nitrogen and kept at $-80^{\circ} \mathrm{C}$ until processing. The sampled palsa, bog, and fen habitats were directly adjacent, such that all cores were collected within a $120 \mathrm{~m}$ radius. For this work, viruses were analyzed from $20-24 \mathrm{~cm}$ deep peat, from three cores at each of the three habitats. For Experiment 1 (DNA extraction), 18 samples were used ( 9 bog and 9 fen), with $10 \pm 1 \mathrm{~g}$ of soil per sample. For Experiment 2 (virion lysis and purification), 36 samples were used (12 palsa, 12 bog, and 12 fen) with $7.5 \pm 1 \mathrm{~g}$ of soil per sample.

\section{Experiment 1: Optimizing DNA extraction}

Viruses were resuspended using a previously optimized method for these soils (Trubl et al. 2016) with minor adjustments. Briefly, $10 \mathrm{ml}$ of a $1 \%$ potassium citrate resuspension buffer amended with $10 \%$ phosphate buffered-saline and $150 \mathrm{mM}$ magnesium sulfate was added to $10 \pm 0.5$ g peat (AKC' buffer). Viruses were physically dispersed via $1 \mathrm{~min}$ of vortexing, $30 \mathrm{~s}$ of manual shaking, and then $15 \mathrm{~min}$ of shaking at $400 \mathrm{rpm}$ at $4{ }^{\circ} \mathrm{C}$. The samples were then centrifuged for $20 \mathrm{~min}$ at $1,500 \times \mathrm{g}$ at $4{ }^{\circ} \mathrm{C}$ to pellet debris, and the supernatant was transferred to new tubes. The resuspension steps above were repeated two more times and the supernatants were combined, and then filtered through a $0.2 \mu \mathrm{m}$ polyethersulfone membrane filter to remove particles and cells and transferred into a new $50 \mathrm{ml}$ tube. The filtrate was then purified via overnight treatment with DNase I (Kunitz units; ThermoFisher, Waltham, Massachusetts) at a $1: 10$ dilution at $4^{\circ} \mathrm{C}$, inactivated by adding a final concentration of $10 \mathrm{mM}$ EDTA and EGTA and mixing for 1 hour. All viral particles were further purified by $\mathrm{CsCl}$ density gradients, established with five $\mathrm{CsCl}$ density layers of $\rho 1.2,1.3,1.4,1.5$, and $1.65 \mathrm{~g} / \mathrm{cm}^{3}$; we included a $1.3 \mathrm{~g} / \mathrm{cm}^{3} \mathrm{CsCl}$ layer to collect ssDNA viruses (Thurber et al. 2009). After density gradient centrifugation of the viral particles, we collected and pooled the $1.3-1.52 \mathrm{~g} / \mathrm{cm}^{3}$ range from the gradient for viral DNA extraction. The viral DNA was extracted (same elution volume) using one of three methods: Wizard mini columns (Wizard; Promega, Madison, WI, products

Peer) reviewing PDF | (2019:03:35625:2:0:NEW 31 May 2019) 
196 A7181 and A7211), cetyl trimethylammonium bromide (CTAB; Porebski, Bailey, and Baum

197

198

199

200

201

202

203

204

205

206

207

208

209

210

211

212

213

214

215

216

217

218

219

220

221

222

223

224

225

226

227

228

229

230

231

232

233

234
1997), or modified DNeasy PowerSoil DNA extraction kit (C3 reagent was $1 / 3$ of working volume and $\mathrm{C} 4$ reagent was $1.5 \mathrm{x}$ working volume) with heat lysis $\left(10 \mathrm{~min}\right.$ incubation at $70^{\circ} \mathrm{C}$, vortexing for $5 \mathrm{~s}$, and $5 \mathrm{~min}$ more of incubation at $70^{\circ} \mathrm{C}$ ) (PowerSoil; Qiagen, Hilden, Germany, product 12888). The extracted DNA was further cleaned up with AMPure beads (Beckman Coulter, Brea, CA, product A63881). DNA purity was assessed with a Nanodrop 8000 spectrophotometer (Implen $\mathrm{GmbH}$, Germany) by the reading of A260/A280 and A260/A230, and quantified using a Qubit 3.0 fluorometer (Invitrogen, Waltham, Massachusetts). DNA sequencing libraries were prepared using Swift Accel-NGS 1S Plus DNA Library Kit (Swift BioSciences, Washtenaw County, Michigan), and libraries were determined to be 'successful' if there was a smooth peak on the Bioanalyzer with average fragment size of $<1 \mathrm{~kb}$ (200-800 bp ideal) and minimal-to-no secondary peak at $\sim 200$ bp (representing concatenated adapters) (Fig. S1), and <20 PCR cycles were required for sequencing. Six libraries were successful (two from bog and four from fen) and required 15 PCR cycles. The successful libraries were sequenced using Illumina HiSeq (300 million reads, 2 x 100 bp paired-end) at JP Sulzberger Columbia Genome Center.

\section{Experiment 2: Optimizing particle lysis and purification}

Viromes were generated as in Experiment 1 with minor changes. First, viruses were resuspended as described for Experiment 1, except half of the samples were not purified with $\mathrm{CsCl}$ density gradient centrifugation. This was to follow-up on our previous work that suggested $\mathrm{CsCl}$ resulted in potentially a major loss of viruses (Trubl et al. 2016). Second, DNA was extracted from all samples using the PowerSoil method, but the physical method of particle lysis was tested by half of the samples undergoing the standard heat lysis as above and the other half undergoing the alternative PowerSoil bead-beating step (with $0.7 \mathrm{~mm}$ garnet beads). Third, the extracted DNA was further cleaned up with DNeasy PowerClean Pro Cleanup Kit (Qiagen, Hilden, Germany, product 12997), instead of AMPure beads. Assessment of microbial contamination was done via qPCR (pre and post-cleanup) with primer sets $1406 \mathrm{f}\left(5^{\prime}\right.$ GYACWCACCGCCCGT-3') and 1525r (5'-AAGGAGGTGWTCCARCC-3') on $5 \mu$ l of sample input to amplify bacterial and archaeal 16S rRNA genes as previously described (Woodcroft et al. 2018). Finally, the 12 palsa samples were sequenced at the Joint Genome Institute (JGI; Walnut creek, CA), where library preparation was performed using the Accel-NGS 1S Plus kit. All viromes required 20 PCR cycles, except $-\mathrm{CsCl}$, bead-beating which required 18 . All libraries were sequenced using the Illumina HiSeq-2000 1TB platform ( 2 x 151 bp paired-end).

\section{Bioinformatics and statistics}

The same informatics and statistics approaches were applied to viromes from Experiments 1 and 2. The sequences were quality-controlled using Trimmomatic (Bolger, Lohse, and Usadel 2014), adaptors were removed, reads were trimmed as soon as the average perbase quality dropped below 20 on 4 nt sliding windows, and reads shorter than 50 bp were discarded, with an additional $10 \mathrm{bp}$ removed from the beginning of read pair one and the end of read pair two to remove the low complexity tail specific to the Accel-NGS 1S Plus kit, per the

Peer] reviewing PDF | (2019:03:35625:2:0:NEW 31 May 2019) 
235

236

237

238

239

240

241

242

243

244

245

246

247

248

249

250

251

252

253

254

255

256

257

258

259

260

261

262

263

264

265

266

267

268

269

270

271

272

273

manufacturer's instruction. Reads were assembled using SPAdes (Bankevich et al. 2012; singlecell option, and k-mers 21, 33, and 55), and the contigs were processed with VirSorter to distinguish viral from microbial contigs (virome decontamination mode; Roux et al. 2015).

Contigs that were selected as VirSorter categories 1 and 2 were used to identify dsDNA viral contigs (as in Trubl et al. 2018). ssDNA viruses, due to short genomes and highly divergent hallmark genes, can frequently be missed by automatic viral sequence identification tools (e.g. VirSorter from Roux et al. 2015 or VirFinder in Ren et al. 2017). We therefore applied a twostep approach to ssDNA identification. First, we identified circular contigs that matched ssDNA marker genes from the PFAM database (Viral_Rep and Phage_F domains), using hmmsearch (Eddy, 2009; HMMER v3; cutoffs: score $\geq 50$ and e-value $\leq 0.001$ ). This identified four Phage_Fencoding and five Viral_Rep-encoding circular contigs, i.e. presumed complete genomes. Second, 2 new HMM profiles were generated, using the protein sequences from the nine identified circular viral contigs, and used to search (hmmsearch with the same cutoffs) the viromes' predicted proteins. This resulted in a final set of 23 predicted ssDNA contigs identified across nine viromes (Table S1).

The viral contigs were clustered at $95 \%$ average nucleotide identify (ANI) across $85 \%$ of the contig (Roux et al. 2018) using nucmer (Delcher, Salzberg, and Phillippy 2003). The same contigs were also compared by BLAST to a pool of potential laboratory contaminants (i.e. Enterobacteria phage PhiX17, Alpha3, M13, Cellulophaga baltica phages, and Pseudoalteromonas phages), and any contigs matching a potential contaminant at more than $95 \%$ ANI across $80 \%$ of the contig were removed. Viral operational taxonomic units (vOTUs) were defined as non-redundant (i.e. post-clustering) viral contigs $>10 \mathrm{~kb}$ for dsDNA viruses (from VirSorter categories 1 or 2; Roux et al. 2015) and circular contigs from 4-8 kb for Microviridae viruses or $1-5 \mathrm{~kb}$ for circular replication-associated protein (Rep)-encoding ssDNA (CRESS DNA) viruses. The vOTUs represent populations that are likely species-level taxa and there is extensive literature context supporting this new standard terminology, which is summarized in a recent consensus paper (Roux et al. 2018). The relative abundance of vOTUs was estimated based on post-QC reads mapping at $\geq 90 \% \mathrm{ANI}$ and covering $>10 \%$ of the contig (Paez-Espino et al. 2016; Roux et al. 2018) using Bowtie2 (Langmead and Salzberg 2012).

Figures were generated with R, using packages Vegan for diversity (Oksanen et al. 2016) and ggplot2 (Wickham 2016) or pheatmap (Kolde 2012) for heatmaps. Hierarchical clustering (function pvclust; method.dist="euclidean" and method.hclust="complete") was conducted on Bray-Curtis dissimilarity matrices using 1000 bootstrap iterations and only the approximately unbiased (AU) bootstrap values were reported.

\section{Data availability}

The 18 viromes from Experiments 1 and 2 are available at the IsoGenie project database under data downloads at https://isogenie.osu.edu/ and at CyVerse (https://www.cyverse.org/) file path /iplant/home/shared/iVirus/Trubl_Soil_Viromes. Data was processed using The Ohio Supercomputer Center (Ohio Supercomputer Center 1987). The final optimized protocol can be 
274

275

276

277

278

279

280

281

282

283

284

285

286

287

288

289

290

291

292

293

294

295

296

297

298

299

300

301

302

303

304

305

306

307

308

309

310

311

312

accessed here: https://www.protocols.io/view/soil-viral-extraction-protocol-for-ssdna-ampdsdna-tzzep76.

\section{Results and Discussion}

Two independent experiments were performed to optimize the generation of quantitatively-amplified viromes from soil samples (Fig. 1). Experiment 1 evaluated three different DNA extraction methods for DNA yield, purity, and successful virome generation on the challenging humic-laden bog and fen soils. Experiment 2 compared two viral particle purification methods (with or without $\mathrm{CsCl}$ ) and two virion lysis methods (heat vs beadbeating), for DNA yield, microbial DNA contamination, and successful virome generation for all three site habitats (palsa, bog and fen). An optimized virome generation protocol was determined for these palsa, bog and fen soils.

Experiment 1: Different DNA extraction methods display variable efficiencies and recover distinct vOTUs

In Experiment 1, three DNA extraction methods were evaluated for DNA yield and purity: PowerSoil DNA extraction kits, Wizard mini columns, and a classic molecular biological approach using cetyl trimethylammonium bromide (CTAB). The PowerSoil kit was designed for humic-rich soils, which dominate our site (Hodgkins et al. 2014; Normand et al. 2017), and has performed well previously for viral samples (Iker et al. 2013). Wizard mini columns were used previously to generate viromes from these soils (Trubl et al. 2018). CTAB performs well on polysaccharide-rich samples (Porebski, Bailey, and Baum 1997), such as our site's peat soils.

Overall, the PowerSoil kit performed best, with the highest DNA yields and increased purity which led to more successful libraries and identification of more vOTUs in the soils tested (bog and fen). Specifically, the PowerSoil kit generally yielded the most DNA (6.34 \pm 0.94 in bog and $13.64 \pm 4.95$ in fen), although the increase was only significant in the fen habitat (one-way ANOVA, $\alpha 0.05$, and Tukey's test with p-value <0.05; Fig. 2A). DNA purity, which is also essential to virome generation (since proteins, phenols, and organics can inhibit amplification; reviewed in Alaeddini 2012), was examined via A260:280 (Fig. 2B; for proteins and phenol contamination; Maniatis et al. 1982) and A260:230 ratios (Fig. S2; for carbohydrates and phenols; Maniatis et al. 1982; Tanveer, Yadav, and Yadav 2016). We posited that A260:280 is a more robust predictor of virome success, since previous work showed that A260:230 of DNA extracts had limited correlation to amplification success (Costa et al. 2010; Ramos-Gómez et al. 2014), although both are highly variable for low DNA concentrations typical for soil viral extracts. For bog samples, at least one replicate from each DNA extraction method had a clean sample based on A260:280 (defined as 1.6-2.1). For the fen, both the Wizard and PowerSoil samples were considered clean. One bog PowerSoil sample, and one fen CTAB sample, had unusually high A260:280 ratios, suggesting the presence of leftover extraction reagents in the sample.

Soil microbial metagenome protocols commonly include further DNA clean-up after extraction to remove inhibitory substances commonly seen in soil (summarized in RooseAmsaleg, Garnier-Sillam, and Harry 2001; Roslan, Mohamad, and Omar 2017), therefore we 
313

314

315

316

317

318

319

320

321

322

323

324

325

326

327

328

329

330

331

332

333

334

335

336

337

338

339

340

341

342

343

344

345

346

347

348

349

350

351

352

evaluated the potential improvement in viral DNA purity from clean-up by AMPure beads. Purity (measured via A260:280) improved significantly in the bog PowerSoil + AMPure samples and was best in the CTAB + AMPure samples, while in the fen, onlyPowerSoil extracts showed improvment. For A260:230, all post-clean-up DNAs were still below the standard minimum threshold (1.6-2.2, Fig. S2).

Although DNA extract yield and purity metrics are useful indicators of extract quality, the goal is successful library preparation and sequencing. Thus, we used the cleaned-up DNA to attempt virome generation, which revealed that PowerSoil-derived DNA was more amenable to library construction than the other extracts. Specifically, five of six PowerSoil extracts successfully generated libraries, whereas only one of the Wizard and none of the CTAB extracts led to successful library construction (threshold for success described in methods). Presumably, the success of the PowerSoil extraction methods was increased due to the kit having been optimized for humic-laden soils (specific reagents proprietary to Qiagen).

Where sequencing library construction was successful, we then sequenced and analyzed the resultant viromes to assess whether the vOTUs captured varied across replicate PowerSoil viromes and between the PowerSoil and Wizard viromes. In total, the 6 viromes produced 1,311 dsDNA viral contigs (VirSorter categories 1 and 2; Roux et al. 2015), which clustered into 516 vOTUs (see methods; Roux et al. 2018). There were dramatic changes in the presence and relative abundance of vOTUs across the two DNA extraction kits evaluated, the biological replicates, and the soil habitats, which is partially the result of uneven coverage due to the 15 rounds of PCR performed to amplify the DNA (Fig. S3). While PCR amplification is a powerful tool that permits ecological interpretation of resulting viral data (Duhaime and Sullivan 2012; Solonenko and Sullivan 2013; Solonenko et al. 2013), library amplification can lead to an enrichment in short inserts, resulting in uneven coverage, a bias that scales with the number of PCR cycles performed (Roux et al. 2019). The differences in vOTU presence/absence among viromes decreased but remained noticeable even when using the most sensitive thresholds proposed for the detection of a vOTU in a metagenome (Roux et al. 2019, Fig. S3). This suggests bias from the DNA extraction method (as reported previously for microbial populations; Delmont et al. 2011; Zielińska et al. 2017), and/or haphazard detection of low-abundance vOTUs due to inadequate sampling and/or sequencing depth.

Experiment 2: Heat-based lysis of non-CsCl-purified virus particles provides the most comprehensive viromes

The results of Experiment 1 identified PowerSoil as the optimal DNA extraction kit (yielding the most successful viromes), so we conducted a second experiment (Experiment 2), independent of the first, to evaluate whether density-based particle purification and/or alternative virion lysis methods could increase viral DNA yield, as previously suggested (Delmont et al. 2011; Zielińska et al. 2017). We reasoned that purification by cesium-chloride ( $\mathrm{CsCl}$ ) density gradients could result in viral loss (as previously described in Trubl et al. 2016), but also lead to reduced microbial DNA and particulate (e.g. clay or organic material) contamination by removing ultra-small $(<0.2 \mathrm{um})$ cells, known to be present in these soils 
353 (Emerson et al. 2018; Trubl et al. 2018) or material that passes the filtration step. For lysis

354

355

356

357

358

359

360

361

362

363

364

365

366

367

368

369

370

371

372

373

374

375

376

377

378

379

380

381

382

383

384

385

386

387

388

389

390

391

392

393

394 would work better because it has been used previously on viruses (reviewed in McCance 1996) and the bead-beating method was previously shown to cause $\sim 27 \%$ more viral loss than not using beads with PowerSoil extraction kit on diverse soils (Iker et al. 2013).

To assess this, viruses were resuspended from three palsa, bog, and fen samples as previously described (Trubl et al. 2016), and then the samples were split with half undergoing particle purification via $\mathrm{CsCl}$ gradients and half not, and each purification treatment lysed by each of the two lysis methods (heat and bead beating) for a total of 4 treatments, all followed by PowerSoil extraction (Fig. 1). We found significant differences in DNA yield due to purification and lysis method choice (Fig. 3, one-way ANOVA, $\alpha$ 0.05, and Tukey's test with pvalue $<0.05)$. CsCl purification had the most impact: yield was higher without it than with it for all but one sample (Bog, $-\mathrm{CsCl}[\mathrm{BB}])$. Lysis method also mattered, with heat producing significantly higher DNA yield than bead-beating ( $t$ test, $\mathrm{p}$-value $<0.05$ ), for the $-\mathrm{CsCl}$ samples in the palsa and fen samples (not significant in the bog) (Fig. 3). These findings suggest that DNA yields were highest when $\mathrm{CsCl}$ density gradients were omitted and viral particles were lysed using heat.

Higher DNA yields could result from contaminating (i.e. non-viral) DNA, so we quantified microbial DNA in all extracts via 165 rRNA gene qPCR (Fig. 4). Surprisingly, we generally observed higher microbial contamination in the CsCl-purified samples (Fig. 4, one-way ANOVA, $\alpha 0.05$, and Tukey's test with $p$-value $<0.05)$, and this varied along the thaw gradient with palsa contamination being higher than that of bog and fen samples. Since residual soil organics can interfere with PCR (Kontanis and Reed, 2006), we repeated the qPCR assay after DNA purification with the PowerClean kit. Generally, microbial contamination increased for $-\mathrm{CsCl}$ samples (Fig. 4), suggesting that their previously low microbial contamination was due to PCR inhibition, and $+\mathrm{CsCl}$ samples had mixed results, but in each habitat $+\mathrm{CsCl}[\mathrm{BB}]$ samples had a significant increase in measurable contamination (Fig. 4). All treatments had higher qPCR-based microbial contamination after PowerClean, except $+\mathrm{CsCl}[\mathrm{H}]$ samples which averaged a 1.5-26fold reduction. Overall there was still no consistent, or significant, improvement in microbial contamination from inclusion of a $\mathrm{CsCl}$ purification step, even after PowerClean treatment.

Since we sequenced bog and fen viromes to characterize treatment effects on the viral signal in Experiment 1, we opted in Experiment 2 to do this evaluation on the 12 Palsa samples, which were all sequenced. We found that the higher DNA yields in the - $\mathrm{CsCl}$ samples led to 3fold more viral contigs, which were also an average of 2.3-fold larger than $+\mathrm{CsCl}$ samples (Fig. $5 A$ ). The results from heat-lysis samples were more modest as they resulted in only $~ 33 \%$ more viral contigs, and statistically indistinguishable contig sizes across treatments (Fig. 5B; unequal variance t-test, $p$-value $>0.05$ ). These findings suggest that the optimal combination for recovering virus genomes from these soils may be to skip $\mathrm{CsCl}$ purification, but still using some form of purification method (DNase used here), and lyse the resultant viral particles using heat.

We next evaluated whether vOTU representation and diversity estimates from the same samples varied across the purification and lysis methods tested here. DNA quantification of 9 out of the 12 viromes showed non-detectable amounts of DNA, but we identified vOTUs in each 
395

396

397

398

399

400

401

402

403

404

405

406

407

408

409

410

411

412

413

414

415

416

417

418

419

420

421

422

423

424

425

426

427

428

429

430

431

432

433

434

of the 12 palsa viromes, suggesting the Accel-NGS 1S Plus kit amplifies DNA from the picogram range. In total, 66 vOTUs were identified with $100 \%$ of the vOTUs identified in -CsCl samples, $89 \%$ (59) identified in the $+\mathrm{CsCl}$ samples, and vOTUs identified by both datasets displaying an average of 30 -fold more coverage (Fig. 6) in - $\mathrm{CsCl}$ viromes. This indicates that the $\mathrm{CsCl}$ purification step reduced the samples to a subset of the initial viral community, it did not help recover virus genomes that would be missed otherwise, and confirmed that the 16S rRNA gene copies identified from the qPCR analyses were likely microbial contamination and not the result of $16 \mathrm{~S}$ rRNA gene copies carried by viruses (Ghosh et al. 2008). Profiles of the recovered communities clustered first by soil core (AU branch supports $>76$ ), then mostly by purification (AU branch supports $>66$ ), and lastly by lysis, and did not change after varying the threshold for considering a lineage present (Fig. S4). Collectively this suggests that differences introduced by sample preparation were outweighed by the distinctiveness of each core's viral community. We proceeded to use diversity metrics to evaluate the different methods' impacts. The alpha diversity metrics paralleled treatment DNA yields where $-\mathrm{CsCl}$ samples were on average $56 \%$ more diverse than the $+\mathrm{CsCl}$ samples, and heat samples were on average $83 \%$ more diverse than the bead-beating samples (Fig. S5A). A comparison of dissimilarities among samples suggested the lysis method had more of an impact, although this effect was variable between samples and thus not statistically significant overall (Fig. S5B).

ssDNA viruses are recovered in all 3 habitats

Previous viromic studies have been limited to describing dsDNA viruses or using MDA to describe ssDNA viruses, but with the onset of the Accel-NGS 1S Plus kit, we leveraged the quantitatively-amplified viromics data produced here to investigate the diversity and relative abundance of ssDNA viruses in our soil samples. Culture collections have revealed ssDNA viruses commonly infect plants as opposed to bacteria, but their distributions in soils remain poorly explored outside a handful of papers which suggest they are highly diverse (Kim et al. 2008; Reavy et al. 2015; Green et al. 2018). Notably, the first quantitative ssDNA/dsDNA viromes suggested that identifiable ssDNA viruses represent a few percent of the viruses observed in marine and freshwater systems (Roux et al. 2016).

To assess this biological signal in soils, we investigated the recovery and relative abundance of ssDNA viruses across our different soil habitats and sample preparations. Overall, we identified 35 putative ssDNA viruses, 11 from the Microviridae family and 24 CRESS DNA viruses (Fig. 7), which clustered into 13 vOTUs (3 Microviridae and 10 CRESS DNA). These sSDNA VOTUs were only a small fraction of the total vOTUs identified in each habitat ( $1 \%$ in bog and fen, and $8 \%$ in palsa) and only bog and fen samples included both types (Microviridae and CRESS-DNA), while palsa samples included exclusively CRESS-DNA viruses (Table S1). This suggests that, as for dsDNA viruses, the composition of the ssDNA virus community varies along the thaw gradient, potentially as a result of known changes in the host communities (Trubl et al. 2018), both microbial (Mondav et al. 2017; Woodcroft et al. 2018) and plant (Hodgkins et al. 2014; Normand et al. 2017). Notably, bead-beating-lysis samples did not include any ssDNA viruses. We posit that this was likely due to the heterogeneity of soil, because ssDNA viruses 
435

436

437

438

439

440

441

442

443

444

445

446

447

448

449

450

451

452

453

454

455

456

457

458

459

460

461

462

463

464

465

466

467

468

469

470

471

472

473

474

have previously been identified from experiments that used a bead-beating lysis (Hopkins et al. 2014). Finally, ssDNA viruses represented on average $4 \%$ of the community in the samples where ssDNA and dsDNA viruses were detected, which suggests that ssDNA viruses are not the dominant type of virus in these soils.

Conclusions

The development of a sample-to-sequence pipeline for ssDNA and dsDNA viruses in soils is crucial for characterizing viruses and their impact in these ecosystems. Our work here built upon previous work that optimized virus resuspension from peatland soils by evaluating DNA extraction and lysis methods to increase DNA yields and purity. Additionally, this is the first evaluation of the Accel-NGS 1S Plus kit to capture ssDNA viruses in soils and our data suggests it is also capable of amplifying DNA down to the picogram range. Although these efforts have made inroads towards characterizing the soil virosphere, several challenges remain. Initial challenges arise from resuspension and enumeration of "fake" virus particles (Ackermann and Tiekotter 2012; Forterre et al. 2013), the lack of data on what fraction of the free virus particles are being recovered from soils, and how to achieve a holistic sampling of the virus community (i.e. dsDNA, ssDNA, and RNA viruses). After viruses are resuspended from soils and their nucleic acid is extracted, there is still a need for amplification which can cause downstream issues (e.g. uneven coverage). Beyond these, the presence of non-viral DNA in capsids or vesicles, e.g. gene transfer agents, can dilute the viral signal in metagenomes and complicate interpretation (reviewed in Roux et al. 2013; Hurwitz, Hallam and Sullivan 2013; Lang and Beatty 2010), although new methods are being developed to identify and characterize these contaminating agents (reviewed in Lang, Westbye, Beatty 2017). Given all the known contaminants that can pass through filtration and their unknown densities or impact on DNA extraction and amplification, we caution the removal of the $\mathrm{CsCl}$ purification without further assessment on additional soils.

In addition to optimization of methods to characterize soil viruses, there are many techniques that can be implemented that will greatly advance our knowledge of viruses in soils. The advent of long-read sequencing technologies have recently been applied to viromics and can improve contig generation for regions of genome with high similarity or complexity (summarized in Roux et al. 2017; Karamitros et al. 2018) and prevent formation of chimeric contigs. Longer-read viromes can thereby not only increase vOTU recovery but also provide resolution of hypervariable genome regions with niche-defining genes, and help capture microdiverse populations missed by short-read assemblies (Warwick-Dugdale et al. 2019). Next, inferences of viral impacts on microbial communities and $\mathrm{C}$ cycling will require predicting hosts both in silico (Edwards et al. 2015; Paez-Espino et al. 2017) and in vitro (Deng et al. 2014; Brum \& Sullivan 2015; Cenens et al. 2015), approaches to which are emerging. Finally, identification of the active viral community and characterization of their roles in biogeochemical processes can be better resolved with techniques like stable isotope-based approaches linked with nanoscale secondary ion mass spectrometry (NanoSIP; Pacton et al. 2014; Pasulka et al. 2018; Gates et al. 2018). Application of these and other approaches to soil viromics will increase and

Peer) reviewing PDF | (2019:03:35625:2:0:NEW 31 May 2019) 
475

476

477

478

479

480

481

482

483

484

485

486

487

488

489

490

491

492

493

494

495

496

497

498

499

500

501

502

503

504

505

506

507

508

509

510

511

512

diversify publicly available viral datasets, advance our understanding of soil viral ecology, and improve our knowledge of viral roles in soil ecosystems.

Acknowledgments

We thank Michelle Carlson from Qiagen for her support and technical advice. We thank Olivier Zablocki for his suggestions and comments on the manuscript. We thank Moira Hough, Sky Dominguez, and Nicole Raab for collecting the soil cores and geochemical data, and the Abisko Naturvetenskapliga Station for field support.

References

Ackermann, H.W. and Tiekotter, K.L., 2012. Murphy's law-If anything can go wrong, it will: Problems in phage electron microscopy. Bacteriophage, 2(2), pp.122-129.

Alaeddini, R., 2012. Forensic implications of PCR inhibition-a review. Forensic Science International: Genetics, 6(3), pp.297-305.

Amgarten, D.E., Braga, L.P.P., Da Silva, A.M. and Setubal, J.C., 2018. MARVEL, a Tool for Prediction of Bacteriophage Sequences in Metagenomic Bins. Frontiers in genetics, 9, p.304.

Bankevich, A., Nurk, S., Antipov, D., Gurevich, A.A., Dvorkin, M., Kulikov, A.S., Lesin, V.M., Nikolenko, S.I., Pham, S., Prjibelski, A.D. and Pyshkin, A.V., 2012. SPAdes: a new genome assembly algorithm and its applications to single-cell sequencing. Journal of computational biology, 19(5), pp.455-477.

Binga, E.K., Lasken, R.S. and Neufeld, J.D., 2008. Something from (almost) nothing: the impact of multiple displacement amplification on microbial ecology. The ISME journal, 2(3), p.233

Bolger, A.M. Lohse, M. and Usadel, B. 2014. Trimmomatic: a flexible trimmer for Illumina sequence data. Bioinformatics, p.btu170.

Brum, J.R. and Sullivan, M.B., 2015. Rising to the challenge: accelerated pace of discovery transforms marine virology. Nature Reviews Microbiology, 13(3), p.147.

Cenens, W., Makumi, A., Govers, S.K., Lavigne, R. and Aertsen, A., 2015. Viral transmission dynamics at single-cell resolution reveal transiently immune subpopulations caused by a carrier state association. PLoS genetics, 11(12), p.e1005770.

Costa, J., Mafra, I., Amaral, J.S. and Oliveira, M.B.P., 2010. Detection of genetically modified soybean DNA in refined vegetable oils. European Food Research and Technology, 230(6), pp.915-923.

Delcher, A.L., Salzberg, S.L. and Phillippy, A.M., 2003. Using MUMmer to identify similar regions in large sequence sets. Current protocols in bioinformatics, (1), pp.10-3.

Delmont, T.O., Robe, P., Cecillon, S., Clark, I.M., Constancias, F., Simonet, P., Hirsch, P.R. and Vogel, T.M., 2011. Accessing the soil metagenome for studies of microbial diversity. Applied and Environmental Microbiology, 77(4), pp.1315-1324. 
513 Deng, L., Ignacio-Espinoza, J.C., Gregory, A.C., Poulos, B.T., Weitz, J.S., Hugenholtz, P. and 514 Sullivan, M.B., 2014. Viral tagging reveals discrete populations in Synechococcus viral

515

516

517

518

519

520

521

522

523

524

525

526

527

528

529

530

531

532

533

534

535

536

537

538

539

540

541

542

543

544

545

546

547

548

549

550

551

552 genome sequence space. Nature, 513(7517), p.242.

Duhaime, M.B. and Sullivan, M.B., 2012. Ocean viruses: rigorously evaluating the metagenomic sample-to-sequence pipeline. Virology, 434(2), pp.181-186.

Eddy, S.R., 2009. A new generation of homology search tools based on probabilistic inference. In Genome Informatics 2009: Genome Informatics Series Vol. 23 (pp. 205-211).

Edwards, R.A., McNair, K., Faust, K., Raes, J. and Dutilh, B.E., 2015. Computational approaches to predict bacteriophage-host relationships. FEMS microbiology reviews, 40(2), pp.258272.

Fierer, N., 2017. Embracing the unknown: disentangling the complexities of the soil microbiome. Nature Reviews Microbiology, 15(10), p.579.

Gates, S.D., Condit, R.C., Moussatche, N., Stewart, B.J., Malkin, A.J. and Weber, P.K., 2018. High Initial Sputter Rate Found for Vaccinia Virions Using Isotopic Labeling, NanoSIMS, and AFM. Analytical chemistry, 90(3), pp.1613-1620.

Green, J.C., Rahman, F., Saxton, M.A. and Williamson, K.E., 2018. Quantifying aquatic viral community change associated with stormwater runoff in a wet retention pond using metagenomic time series data. Aquatic Microbial Ecology, 81(1), pp.19-35.

Gregory, A., Zayed, A., Conceição-Neto, N., Temperton, B., Bolduc, B., Alberti, A., Ardyna, M., Arkhipova, K., Carmicheal, M., Cruaud, C. and Dimier, C., 2019. Marine DNA viral macroand micro-diversity from pole to pole. In press. DOI: https://doi.org/10.1016/j.cell.2019.03.040

Han, L., Sun, K., Jin, J. and Xing, B., 2016. Some concepts of soil organic carbon characteristics and mineral interaction from a review of literature. Soil Biology and Biochemistry, 94, pp.107-121.

Hayes, S., Mahony, J., Nauta, A. and van Sinderen, D., 2017. Metagenomic approaches to assess bacteriophages in various environmental niches. Viruses, 9(6), p.127.

Hodgkins, S.B., Tfaily, M.M., McCalley, C.K., Logan, T.A., Crill, P.M., Saleska, S.R., Rich, V.I. and Chanton, J.P., 2014. Changes in peat chemistry associated with permafrost thaw increase greenhouse gas production. Proceedings of the National Academy of Sciences, p.201314641.

Hopkins, M., Kailasan, S., Cohen, A., Roux, S., Tucker, K.P., Shevenell, A., Agbandje-McKenna, M. and Breitbart, M., 2014. Diversity of environmental single-stranded DNA phages revealed by PCR amplification of the partial major capsid protein. The ISME journal, 8(10), p.2093

Hurwitz, B.L., Hallam, S.J. and Sullivan, M.B., 2013. Metabolic reprogramming by viruses in the sunlit and dark ocean. Genome biology, 14(11), p.R123.

Iker, B.C., Bright, K.R., Pepper, I.L., Gerba, C.P. and Kitajima, M., 2013. Evaluation of commercial kits for the extraction and purification of viral nucleic acids from environmental and fecal samples. Journal of virological methods, 191(1), pp.24-30. 
553

554

555

556

557

558

559

560

561

562

563

564

565

566

567

568

569

570

571

572

573

574

575

576

577

578

579

580

581

582

583

584

585

586

587

588

589

590

591

592

Johansson, T., Malmer, N., Crill, P.M., Friborg, T., Aakerman, J.H., Mastepanov, M. and Christensen, T.R., 2006. Decadal vegetation changes in a northern peatland, greenhouse gas fluxes and net radiative forcing. Global Change Biology, 12(12), pp.2352-2369.

Karamitros, T., van Wilgenburg, B., Wills, M., Klenerman, P. and Magiorkinis, G., 2018. Nanopore sequencing and full genome de novo assembly of human cytomegalovirus TB40/E reveals clonal diversity and structural variations. BMC genomics, 19(1), p.577.

Karlsson, O.E., Belák, S. and Granberg, F., 2013. The effect of preprocessing by sequenceindependent, single-primer amplification (SISPA) on metagenomic detection of viruses. Biosecurity and bioterrorism: biodefense strategy, practice, and science, 11(S1), pp.S227-S234.

Kim, K.H., Chang, H.W., Nam, Y.D., Roh, S.W., Kim, M.S., Sung, Y., Jeon, C.O., Oh, H.M. and Bae, J.W., 2008. Amplification of uncultured single-stranded DNA viruses from rice paddy soil. Appl. Environ. Microbiol., 74(19), pp.5975-5985.

Kim, M.S., Whon, T.W. and Bae, J.W., 2013. Comparative viral metagenomics of environmental samples from Korea. Genomics \& informatics, 11(3), pp.121-128.

Kolde, R., 2012. Pheatmap: pretty heatmaps. R package version, 61

Kontanis, E.J. and Reed, F.A., 2006. Evaluation of real-time PCR amplification efficiencies to detect PCR inhibitors. Journal of forensic sciences, 51(4), pp.795-804.

Labonté, J.M. and Suttle, C.A., 2013. Previously unknown and highly divergent ssDNA viruses populate the oceans. The ISME journal, 7(11), p.2169.

Lang, A.S., Westbye, A.B. and Beatty, J.T., 2017. The distribution, evolution, and roles of gene transfer agents in prokaryotic genetic exchange. Annual review of virology, 4, pp.87-104.

Langmead, B. and Salzberg, S.L., 2012. Fast gapped-read alignment with Bowtie 2. Nature methods, 9(4), p.357.

Lehmann, J. and Kleber, M., 2015. The contentious nature of soil organic matter. Nature, 528(7580), p.60.

Maniatis T., Fritsch E.F., Sambrook J. Molecular cloning: a laboratory manual. Cold Spring Harbor: Cold Spring Harbor Laboratory; 1982.

Marine, R., McCarren, C., Vorrasane, V., Nasko, D., Crowgey, E., Polson, S.W. and Wommack, K.E., 2014. Caught in the middle with multiple displacement amplification: the myth of pooling for avoiding multiple displacement amplification bias in a metagenome. Microbiome, 2(1), p.3.

McCalley, C.K., Woodcroft, B.J., Hodgkins, S.B., Wehr, R.A., Kim, E.H., Mondav, R., Crill, P.M., Chanton, J.P., Rich, V.I., Tyson, G.W. and Saleska, S.R., 2014. Methane dynamics regulated by microbial community response to permafrost thaw. Nature, 514(7523), p.478.

Mondav, R., McCalley, C.K., Hodgkins, S.B., Frolking, S., Saleska, S.R., Rich, V.I., Chanton, J.P. and Crill, P.M., 2017. Microbial network, phylogenetic diversity and community membership in the active layer across a permafrost thaw gradient. Environmental microbiology, 19(8), pp.3201-3218. 
593

594

595

596

597

598

599

600

601

602

603

604

605

606

607

608

609

610

611

612

613

614

615

616

617

618

619

620

621

622

623

624

625

626

627

628

629

630

631

632

Narayan, A., Jain, K., Shah, A.R. and Madamwar, D., 2016. An efficient and cost-effective method for DNA extraction from athalassohaline soil using a newly formulated cell extraction buffer. 3 Biotech, 6(1), p.62.

Narr, A., Nawaz, A., Wick, L.Y., Harms, H. and Chatzinotas, A., 2017. Soil Viral Communities Vary Temporally and along a Land Use Transect as Revealed by Virus-Like Particle Counting and a Modified Community Fingerprinting Approach (fRAPD). Frontiers in microbiology, 8, p.1975.

Normand, A.E., Smith, A.N., Clark, M.W., Long, J.R. and Reddy, K.R., 2017. Chemical composition of soil organic matter in a subarctic peatland: influence of shifting vegetation communities. Soil Science Society of America Journal, 81(1), pp.41-49.

Ohio Supercomputer Center. 1987. Ohio Supercomputer Center. Columbus OH: Ohio Supercomputer Center.

Oksanen, J., Blanchet, F., Kindt, R., Legendre, P. and O'Hara, R., 2016. Vegan: community ecology package. $\mathrm{R}$ package 2.3-3.

Olefeldt, D., Roulet, N.T., Bergeron, O., Crill, P., Bäckstrand, K. and Christensen, T.R., 2012. Net carbon accumulation of a high-latitude permafrost palsa mire similar to permafrost-free peatlands. Geophysical Research Letters, 39(3).

Pacton, M., Wacey, D., Corinaldesi, C., Tangherlini, M., Kilburn, M.R., Gorin, G.E., Danovaro, R. and Vasconcelos, C., 2014. Viruses as new agents of organomineralization in the geological record. Nature communications, 5, p.4298.

Paez-Espino, D., Eloe-Fadrosh, E.A., Pavlopoulos, G.A., Thomas, A.D., Huntemann, M., Mikhailova, N., Rubin, E., Ivanova, N.N. and Kyrpides, N.C., 2016. Uncovering Earth's virome. Nature, 536(7617), p.425.

Paez-Espino, D., Pavlopoulos, G.A., Ivanova, N.N. and Kyrpides, N.C., 2017. Nontargeted virus sequence discovery pipeline and virus clustering for metagenomic data. nature protocols, 12(8), p.1673.

Pasulka, A.L., Thamatrakoln, K., Kopf, S.H., Guan, Y., Poulos, B., Moradian, A., Sweredoski, M.J., Hess, S., Sullivan, M.B., Bidle, K.D. and Orphan, V.J., 2018. Interrogating marine virus-host interactions and elemental transfer with BONCAT and nanoSIMS-based methods. Environmental microbiology, 20(2), pp.671-692.

Phan, T.G., Mori, D., Deng, X., Rajindrajith, S., Ranawaka, U., Ng, T.F.F., Bucardo-Rivera, F., Orlandi, P., Ahmed, K. and Delwart, E., 2015. Small circular single stranded DNA viral genomes in unexplained cases of human encephalitis, diarrhea, and in untreated sewage. Virology, 482, pp.98-104

Porebski, S., Bailey, L.G. and Baum, B.R., 1997. Modification of a CTAB DNA extraction protocol for plants containing high polysaccharide and polyphenol components. Plant molecular biology reporter, 15(1), pp.8-15

Ramos-Gómez, S., Busto, M.D., Perez-Mateos, M. and Ortega, N., 2014. Development of a method to recovery and amplification DNA by real-time PCR from commercial vegetable oils. Food Chemistry, 158, pp.374-383.

Peer] reviewing PDF | (2019:03:35625:2:0:NEW 31 May 2019) 
633

634

635

636

637

638

639

640

641

642

643

644

645

646

647

648

649

650

651

652

653

654

655

656

657

658

659

660

661

662

663

664

665

666

667

668

669

670

671

672

Reavy, B., Swanson, M.M., Cock, P.J., Dawson, L., Freitag, T.E., Singh, B.K., Torrance, L., Mushegian, A.R. and Taliansky, M., 2015. Distinct circular single-stranded DNA viruses exist in different soil types. Appl. Environ. Microbiol., 81(12), pp.3934-3945.

Ren, J., Ahlgren, N.A., Lu, Y.Y., Fuhrman, J.A. and Sun, F., 2017. VirFinder: a novel k-mer based tool for identifying viral sequences from assembled metagenomic data. Microbiome, 5(1), p.69.

Roose-Amsaleg, C.L., Garnier-Sillam, E. and Harry, M., 2001. Extraction and purification of microbial DNA from soil and sediment samples. Applied Soil Ecology, 18(1), pp.47-60.

Rosario, K., Fierer, N., Miller, S., Luongo, J. and Breitbart, M., 2018. Diversity of DNA and RNA viruses in indoor air as assessed via metagenomic sequencing. Environmental science \& technology, 52(3), pp.1014-1027.

Roslan, M.A.M., Mohamad, M.A.N. and Omar, S.M., 2017. High quality DNA from peat soil for metagenomic studies a minireview on dna extraction methods. Science, 1(2), pp.01-06.

Roux, S., Emerson, J.B., Eloe-Fadrosh, E.A. and Sullivan, M.B., 2017. Benchmarking viromics: an in silico evaluation of metagenome-enabled estimates of viral community composition and diversity. PeerJ, 5, p.e3817.

Roux, S., Krupovic, M., Debroas, D., Forterre, P. and Enault, F., 2013. Assessment of viral community functional potential from viral metagenomes may be hampered by contamination with cellular sequences. Open biology, 3(12), p.130160.

Roux, S., Adriaenssens, E.M., Dutilh, B.E., Koonin, E.V, Kropinski, A.M., Krupovic, M., Kuhn, J.H. Lavigne, R., Brister, J.R., Varsani, A., Amid, C., Aziz, R.K., Bordenstein, S.R., Bork, P., Breitbart, M., Cochrane, G.R., Daly, R.A., Desnues, C., Duhaime, M.B., Emerson, J.B., Enault, F., Fuhrman, J.A., Hingamp, P., Hugenholtz, P., Hurwitz, B.L., Ivanova, N.N., Labonté, J.M., Lee, K-B., Malmstrom, R.R., Martinez-Garcia, M., Mizrachi, I.K., Ogata, H., Páez-Espino, D., Petit, M-A., Putonti, C., Rattei, T., Reyes, A., Rodriguez-Valera, F., Rosario, K., Schriml, L., Schulz, F., Steward, G.F., Sullivan, M.S., Sunagawa, S., Suttle, C.A., Temperton, B., Tringe, S.G., Thurber, R.V., Webster, N.S., Whiteson, K.L., Wilhelm, S.W., Wommack, K.E., Woyke, T., Wrighton, K.C., Yilmaz, P., Yoshida, T., Young, M.J., Yutin, N., Allen, L.Z., Kyrpides, N.C., Eloe-Fadrosh, E.A. 2018. Minimum Information about an Uncultivated Virus Genome (MIUViG). Nature Biotechnology, 37(1), 29-37.

Roux, S., Enault, F., Hurwitz, B.L. and Sullivan, M.B., 2015. VirSorter: mining viral signal from microbial genomic data. PeerJ, 3, p.e985 Segobola, J., Adriaenssens, E., Tsekoa, T., Rashamuse, K. and Cowan, D., 2018. Exploring viral diversity in a unique South African soil habitat. Scientific reports, 8(1), p.111.

Roux, S., Trubl, G., Goudeau, D., Nath, N., Couradeau, E., Ahlgren, N.A., Zhan, Y., Marsan, D., Chen, F., Fuhrman, J.A. and Northen, T.R., 2018b. Optimizing de novo genome assembly from PCR-amplified metagenomes (No. e27453v1). PeerJ Preprints.

Roux, S., Solonenko, N.E., Dang, V.T., Poulos, B.T., Schwenck, S.M., Goldsmith, D.B., Coleman, M.L., Breitbart, M. and Sullivan, M.B., 2016. Towards quantitative viromics for both double-stranded and single-stranded DNA viruses. PeerJ, 4, p.e2777.

PeerJ reviewing PDF | (2019:03:35625:2:0:NEW 31 May 2019) 
673

674

675

676

677

678

679

680

681

682

683

684

685

686

687

688

689

690

691

692

693

694

695

696

697

698

699

Solonenko, S.A., Ignacio-Espinoza, J.C., Alberti, A., Cruaud, C., Hallam, S., Konstantinidis, K., Tyson, G., Wincker, P. and Sullivan, M.B., 2013. Sequencing platform and library preparation choices impact viral metagenomes. BMC genomics, 14(1), p.320.

Solonenko, S.A. and Sullivan, M.B., 2013. Preparation of metagenomic libraries from naturally occurring marine viruses. In Methods in enzymology (Vol. 531, pp. 143-165). Academic Press.

Tanveer, A., Yadav, S. and Yadav, D., 2016. Comparative assessment of methods for metagenomic DNA isolation from soils of different crop growing fields. 3 Biotech, 6(2), p.220.

Warwick-Dugdale J, Solonenko N, Moore K, Chittick L, Gregory AC, Allen MJ, Sullivan MB, Temperton B. 2019. Long-read viral metagenomics captures abundant and microdiverse viral populations and their niche-defining genomic islands. PeerJ 7:e6800 https://doi.org/10.7717/peerj.6800.Wickham, H., 2016. ggplot2: elegant graphics for data analysis. Springer.

Wommack, K.E., Bhavsar, J., Polson, S.W., Chen, J., Dumas, M., Srinivasiah, S., Furman, M., Jamindar, S. and Nasko, D.J., 2012. VIROME: a standard operating procedure for analysis of viral metagenome sequences. Stand Genomic Sci 6: 427-439.

Woodcroft, B.J., Singleton, C.M., Boyd, J.A., Evans, P.N., Emerson, J.B., Zayed, A.A., Hoelzle, R.D., Lamberton, T.O., McCalley, C.K., Hodgkins, S.B. and Wilson, R.M., 2018. Genomecentric view of carbon processing in thawing permafrost. Nature, p.1.

Yilmaz, S., Allgaier, M. and Hugenholtz, P., 2010. Multiple displacement amplification compromises quantitative analysis of metagenomes. Nature methods, 7(12), p.943.

Zablocki, O., Adriaenssens, E.M. and Cowan, D., 2016. Diversity and ecology of viruses in hyperarid desert soils. Appl. Environ. Microbiol., 82(3), pp.770-777.

Zielińska, S., Radkowski, P., Blendowska, A., Ludwig-Gałęzowska, A., Łoś, J.M. and Łoś, M., 2017. The choice of the DNA extraction method may influence the outcome of the soil microbial community structure analysis. MicrobiologyOpen, 6(4), p.e00453. 


\section{Figure 1}

Overview of experiments to optimize methods for virome generation.

Two experiments evaluated three DNA extraction methods (A, Experiment 1 in green), two different virion lysis methods, and $\mathrm{CsCl}$ virion purification (B, Experiment 2 in blue), for optimizing virome generation from three peats soils along a permafrost thaw gradient. Nine soil cores were collected in July 2015, three from each habitat, and used to create 18 samples ( 9 bog and 9 fen) with $10 \pm 1 \mathrm{~g}$ of soil in each sample for Experiment 1 and 36 samples (12 palsa, 12 bog, and 12 fen) with $7.5 \pm 1 \mathrm{~g}$ of soil in each sample for Experiment 2; representative photos of cores were taken by Gary Trubl. Viruses were resuspended as previously described in Trubl et al. (2016), but with the addition of a DNase step and a 1.3 $\mathrm{g} / \mathrm{ml}$ layer for $\mathrm{CsCl}$ purification. Red font color indicates the best-performing option within each set. " denotes adapted protocol from Trubl et al. 2016. ${ }^{\# \#}$ indicates that only 12 palsa samples proceeded to library preparation. 
(A) Experiment 1: identify best DNA extraction method

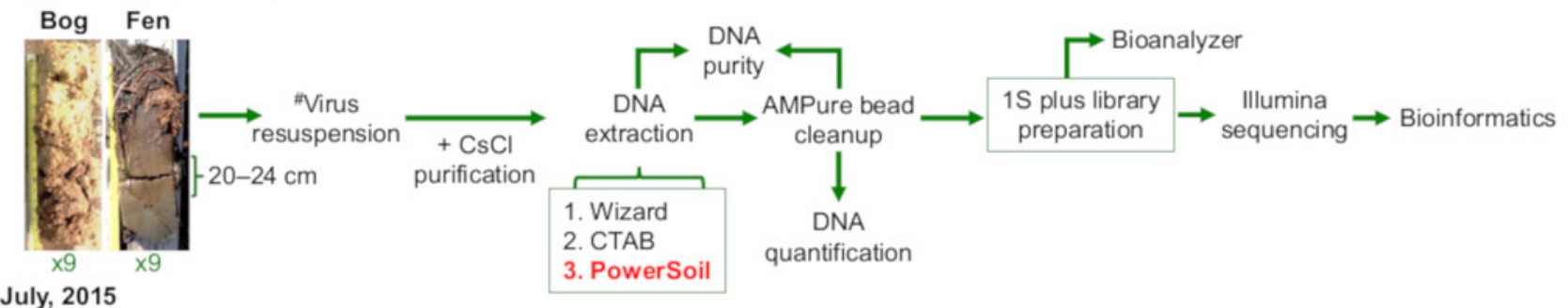

(B) Experiment 2: increase viral DNA and contig yield Palsa Bog Fen

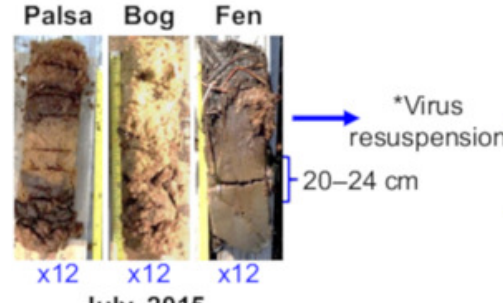

DNA

quantification

July, 2015

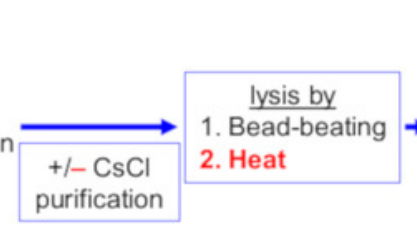

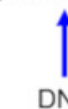

DNA extraction $\rightarrow$ PowerClean $\rightarrow$ (PowerSoil) 1S plus library $\rightarrow$ Illumina preparation $\rightarrow$ Illumina $\rightarrow$ Bioinformatics 


\section{Figure 2}

Impact of extraction methods on DNA yields and purity (Experiment 1).

Bog samples are shown on the left of each panel, fen samples on the right. DNA extraction methods are color-coded: purple for CTAB, blue for Wizard, and green for PowerSoil. * denotes significant difference via one-way ANOVA, $\alpha$ 0.05, and Tukey's test with p-value $<0.05$. ${ }^{\dagger}$ denotes significant difference for t test, $p$-value $<0.05 ;{ }^{\text {tt }}=p$-value $<0.01 ;{ }^{\mathrm{tt}}=\mathrm{p}$ value $<0.001$. A) The DNA concentration $(\mathrm{ng} / \mu \mathrm{l})$ after AMPure purification for the three DNA extraction methods. B) DNA extract purity via A260/A280. Dotted lines are purity thresholds: Acceptable range in yellow shading and preferred range in red shading.
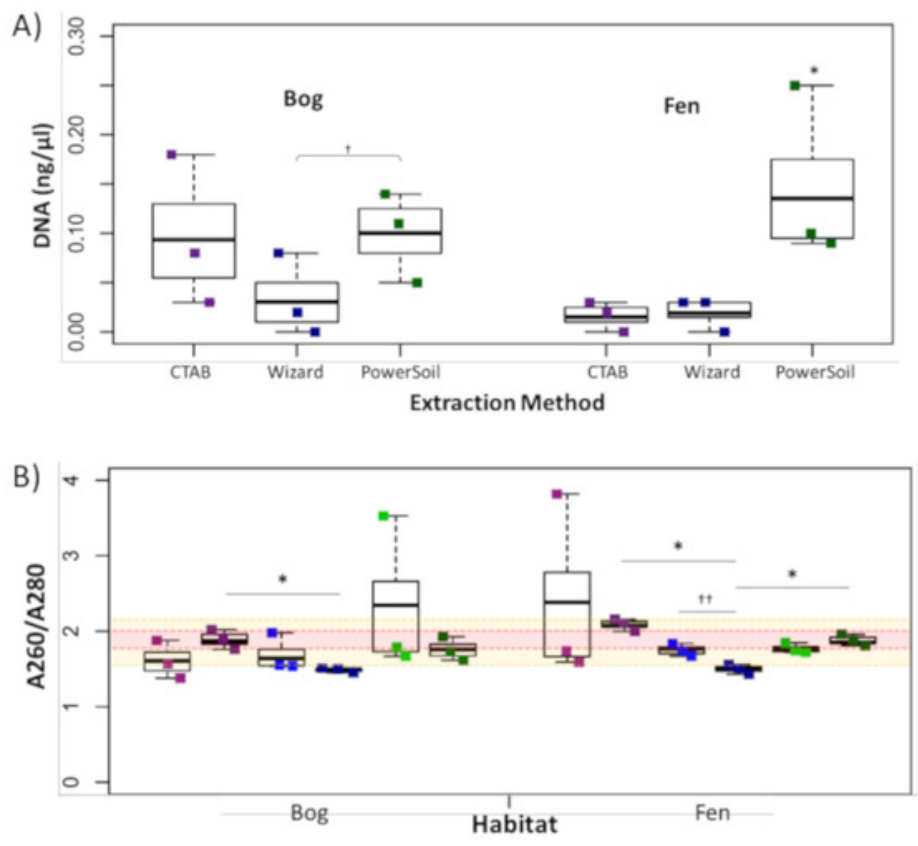
Figure 3

Impact of lysis and purification methods on DNA yields (Experiment 2).

The DNA concentration ( $\mathrm{ng} / \mu \mathrm{ll})$ is given for the two virion lysis methods used, with or without $\mathrm{CsCl}$ purification, for all three habitats. The four treatments are color coded with blue for bead-beating, red for heat lysis and a darker shade if also purified with $\mathrm{CsCl} . *$ denotes significant difference via one-way ANOVA, $\alpha 0.05$, and Tukey's test with $p$-value $<0.05$. \# denotes $n=2$. N/D denotes non-detectable DNA concentration.

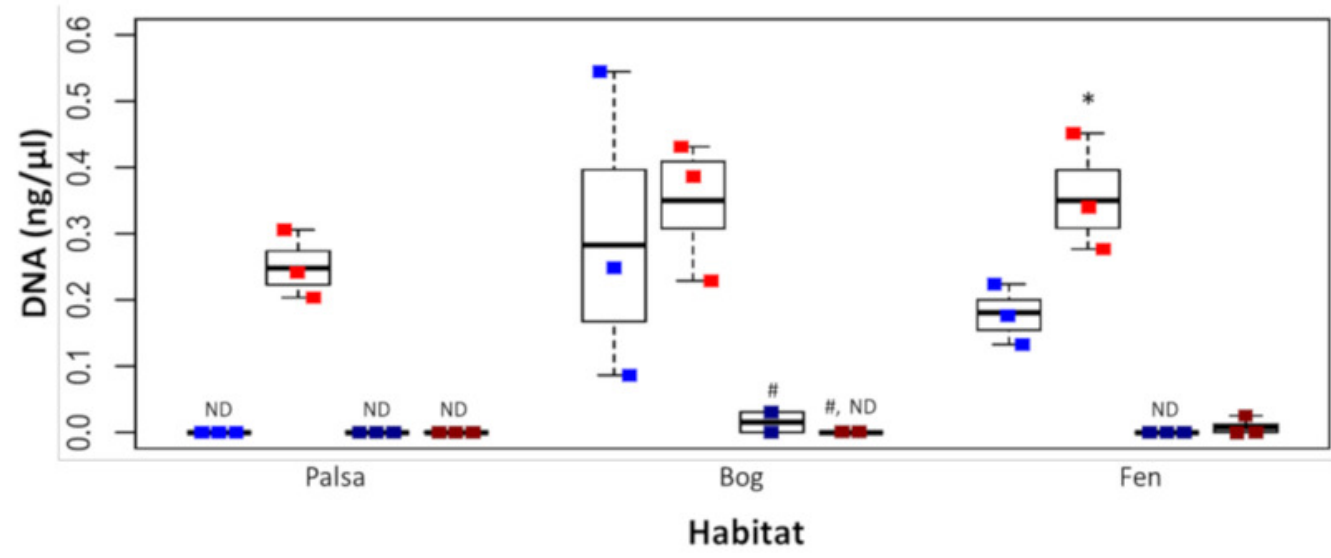

Lysis \& Purification Treatments - $\mathrm{CsCl}$ Bead-beating - $-\mathrm{CsCl}$ Heat 


\section{Figure 4}

Evaluation of microbial contamination (Experiment 2).

The 16S rRNA gene contamination (square root) is indicated for each virome grouped by habitat before (left) and after (right) clean up with PowerClean. The four treatments are color coded with blue for bead-beating and red for heat lysis and a darker shade after $\mathrm{CsCl}$ purification. \# denotes no data available. 16S qPCR primers were 1406F-1525R (Woodcroft et al. 2018). ${ }^{\dagger}$ denotes significant difference for $t$ test, $p$-value $<0.05 ;{ }^{\text {Ht }}=p$-value $<0.01 ;{ }^{\text {Ht }}=p$ value $<0.001$.

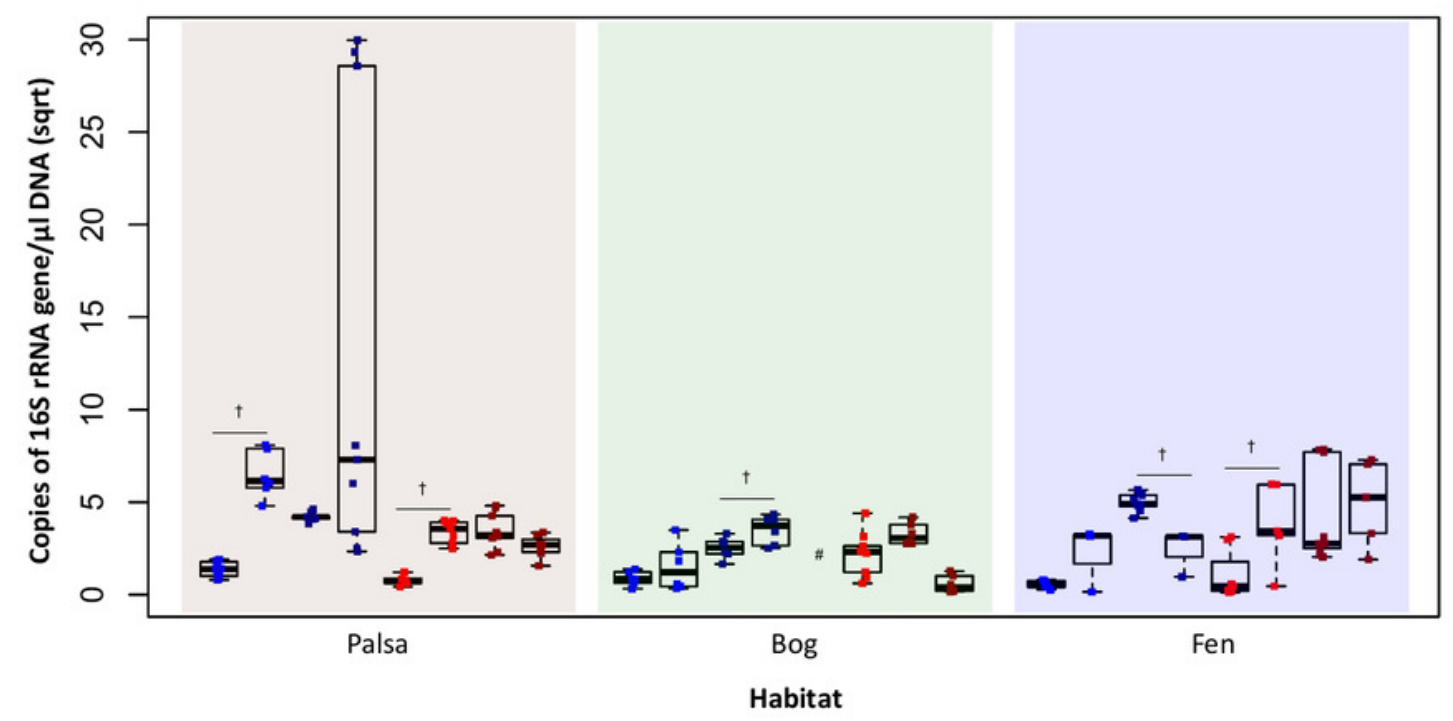

Lysis \& Purification Treatments - $\mathrm{CsCl}$ Bead-beating - $+\mathrm{CsCl}$ Bead-beating - $\mathrm{CsCl}$ Heat $+\mathrm{CsCl} \mathrm{Heat}$ 


\section{Figure 5}

Number and size of assembled viral contigs (Experiment 2).

Boxplots show the number of viral contigs assembled, and those $>10 \mathrm{~kb}$, for each treatment. Viral contigs were identified by two approaches: the "conservative" one included only contigs in VirSorter categories $1 \& 2$ for which a viral origin is very likely, while the "sensitive" one also included contigs in VirSorter category 3, for which a viral origin is possible but unsure.
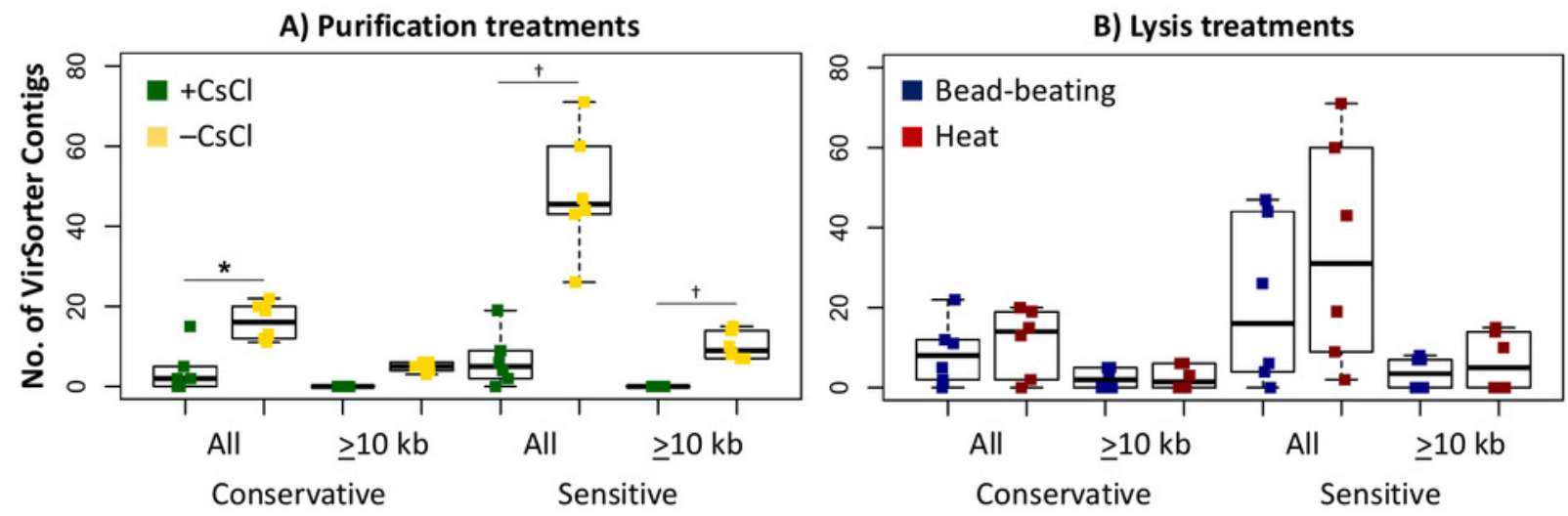

Virus identification approach 


\section{Figure 6}

Relative abundance of vOTUs across 12 palsa viromes (Experiment 2).

A heatmap showing the Euclidean-based hierarchical clustering of a Bray-Curtis dissimilarity matrix calculated from vOTU relative abundances within each virome with an approximately unbiased (AU) bootstrap value $(n=1000)$. The relative abundances were normalized by contig length and per $\mathrm{Gbp}$ of metagenome and were $\log _{10}$ transformed. Reads were mapped to contigs at $\geq 90 \%$ nucleotide identity and the relative abundance was set to 0 if reads covered $<10 \%$ of the contig. Heatmaps with alternative genome coverage thresholds are presented in Fig. S3. Abbreviations: $\mathrm{H}$, heat lysis; $\mathrm{BB}$, bead-beating; $+/-\mathrm{CsCl}$, with or without cesium chloride purification; $\mathrm{C}$, soil core.

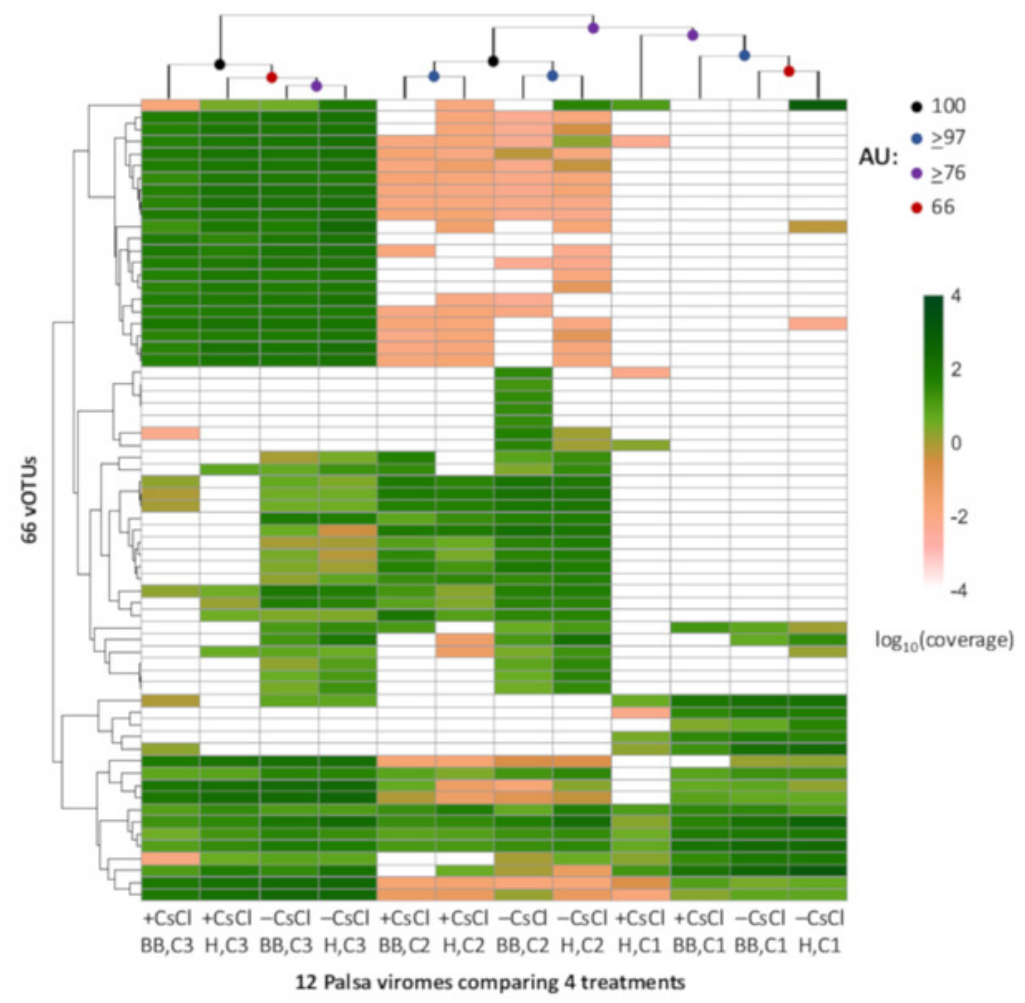




\section{Figure 7}

Recovery of ssDNA viruses across habitats and methods.

A) ssDNA viral contigs from viromes in Experiment 2. The PowerSoil bog samples are grouped, as are the PowerSoil fen samples. The single Wizard virome from the fen habitat is also shown. B) SSDNA viral contigs from viromes in Experiment 2 grouped by the four treatments: $+/-\mathrm{CsCl}$ and bead-beating $[\mathrm{BB}]$ or heat $[\mathrm{H}]$ virion lysis method. $\mathrm{C}$ ) ssDNA viruses from both Experiments are shown and grouped by habitat.
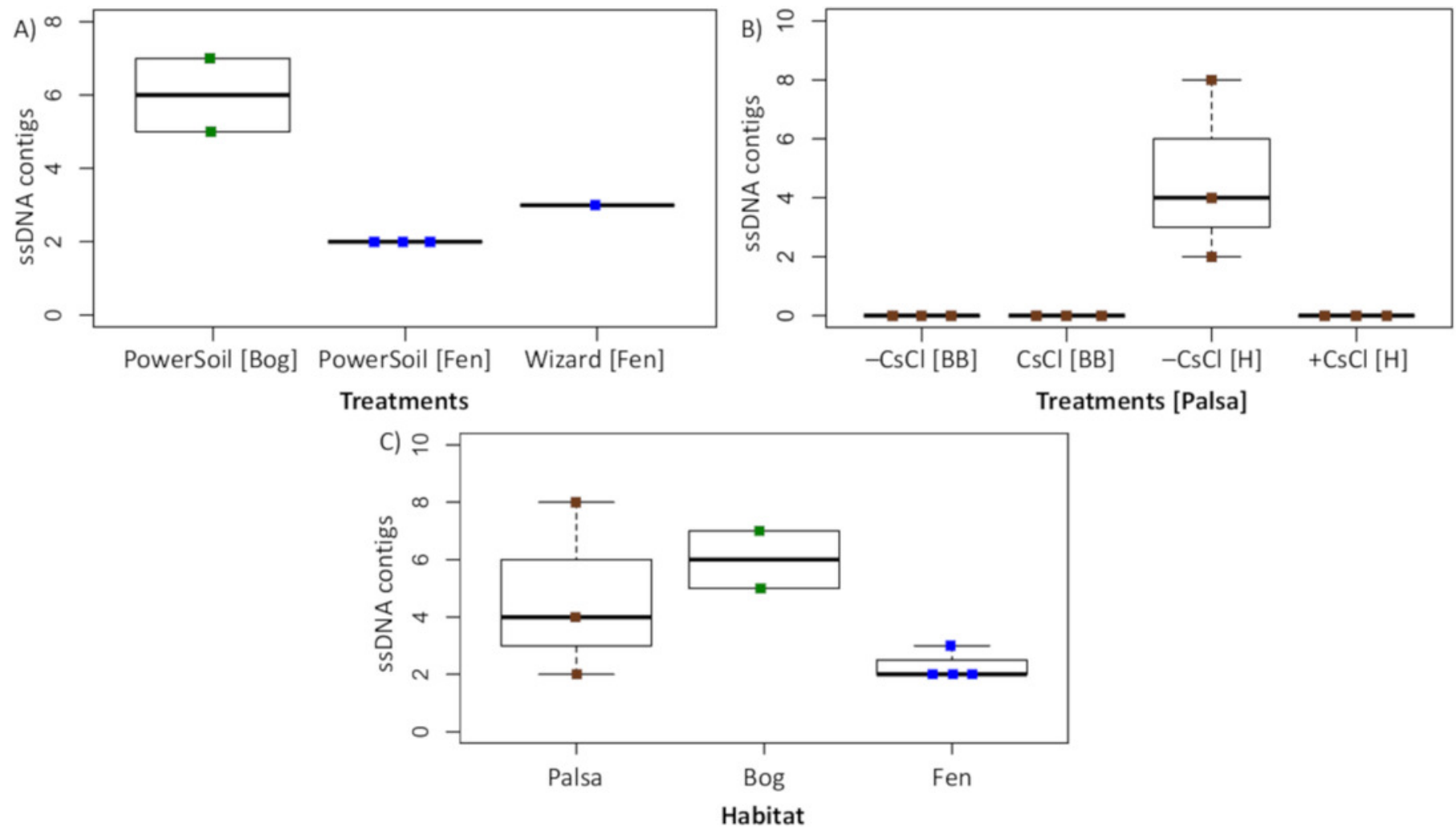